International Journal of Advances in Pharmacy and Biotechnology

Vol.3, Issue-3, 2017, 8-20

Research Article

Open Access

I J A P B

ISSN: 2454-8375

\title{
FORMULATION AND EVALUATION OF FAMOTIDINE ION ACTIVATED INSITU GELLING SYSTEM
}

\author{
A. Geethalakshmi ${ }^{*}$, Lalakia K.H² \\ ${ }^{1}$ Department of Pharmaceutics, R R College of Pharmacy, Bangalore- 560098, Karnataka, India. \\ 2Department of Industrial Pharmacy, Acharya \& B. M. Reddy College of Pharmacy, \\ Bangalore- 560 090, Karnataka, India. \\ *Corresponding author e-mail: geeshwar@gmail.com
}

Received: 10 December 2017

Revised: 21 December 2017

Accepted: 25 December 2017

\begin{abstract}
:
Famotidine, an anti-ulcer agent was chosen as a drug which is a more potent $\mathrm{H}_{2}$ receptor antagonist than ranitidine and cimetidine. The purpose of this research work was to formulate and evaluate Famotidine oral in-situ gelling system for sustained oral drug delivery to overcome its shorter elimination half-life and less protein binding nature. Formulation chart was prepared by applying $3^{2}$ full factorial design using two independent variables, i.e. concentration of gelrite and HPMC K100M. The solution form of prepared formulations was changed into gel by the addition of $0.1 \mathrm{~N} \mathrm{HCl}$. The formulations prepared were evaluated for several physico-chemical parameters like drug-polymer interaction, $\mathrm{pH}$, gelling capacity, drug content uniformity, in vitro drug release, viscosity and anti-ulcer activity (In-vivo study). The stability studies were carried out on the optimized formulation and no significant change was found in physico-chemical properties and in vitro dissolution studies. The best-fit release kinetic was achieved with zero order. The results of a $3^{2}$ full factorial design revealed that the concentrations of gelrite and HPMC K100M significantly affected the dependent variables like viscosity, drug content $(\%)$ and drug release $\left(\mathrm{Q}_{12}\right)$. The results of the invivo study showed that sustained release of drug from the prepared formulation shows better \% protective effect on alcohol induced stomach ulcer compared to that of the marketed conventional tablet. It was concluded that prepared Famotidine in situ gel is a good candidate for controlled oral drug delivery system.
\end{abstract}

Key words: Famotidine; Anti-ulcer; In situ gel; Sustained oral drug delivery; Gelrite; In-vivo study.

\section{INTRODUCTION:}

Objective: In-situ gel forming drug delivery systems are controlled drug delivery system, sol-gel systems. These in situ gels are liquid at room temperature but will undergo gelation when in contact with biological conditions like, $\mathrm{pH}$, ions and temperature of body system. [1]

Gastric emptying is a complex process that is highly variable and makes the in vivo performance of drug delivery systems uncertain. To reduce the dosing frequency, minimize fluctuations in plasma drug concentration and to prolong gastric emptying several attempts were made to develop controlled drug delivery systems. [2-4] Famotidine is a more potent $\mathrm{H}_{2}$ receptor having drawbacks such as low oral bioavailability (40 to $45 \%$ ), less plasma level after multiple doses (15 to $20 \%$ ), first-pass metabolism. The drug has an elimination potential of 65 to $70 \%$ by renal route and 30 
to $35 \%$ of metabolic routes $[5,6]$. These facts led to the focus of this research on stomachspecific oral in-situ gel of Famotidine to reduce its unwanted side effects at other sites by localized and systemic prolonged delivery to stomach ulcers.

\section{MATERIALS AND METHODS}

\subsection{Drug-excipient compatibility studies}

Compatibility studies were carried out to know the possible interactions between Famotidine and excipients used in the formulation. Physical mixtures of drug and excipients were prepared and the compatibility studies were carried out at 600$4000 \mathrm{~cm}^{-1}$ by using FT-IR spectroscopy.

\subsection{Preparation of ion activated in situ gelling system for Famotidine}

Gelrite and HPMC K100M were used as polymers in the formulation of Famotidine. Calcium chloride was used for cation induced gelation in the stomach. Sodium citrate was added to delay the gelation of preparation until the preparation reaches the acid environment of stomach where cation induced gelation occurs.

A Gelrite solution was prepared in $30 \mathrm{ml}$ of deionized water containing sodium citrate; the gelrite was added and heated to $90{ }^{\circ} \mathrm{C}$. It was cooled to $40{ }^{\circ} \mathrm{C}$ (step 1). In $35 \mathrm{ml}$ water, HPMC K100M was dissolved. Calcium chloride and Famotidine were added to it while stirring so that there was proper and homogenous dispersion of the drug (step 2). The solutions from step 1 to step 2 were mixed well. A solution of sodium propyl www.ijapbjournal.com paraben and sweetener in $5 \mathrm{ml}$ of water was added to above mixture and stirred well. Coloring agent (Amaranth) was added to the above mixture. The volume was made up to $100 \mathrm{ml}$ with de-ionized water and stirred well (Table-2) [2].

In the preliminary batches P1 to P5 (Table-1), the concentrations of the gelrite were 0.25$1.25 \%$ and the concentration of HPMC $\mathrm{K} 100 \mathrm{M}$, calcium chloride and sodium citrate were constant at $0.4 \%, 0.016 \%$ and $0.17 \%$ respectively. While in F1 to F9 (Table-2), concentrations of Gelrite $(0.25 \%, 0.50 \%$ and $0.75 \%$ ) were taken as the variable $\mathrm{X}_{1}$ and concentrations of HPMC K100M (0.30\%, 0.40 $\%$ and $0.50 \%$ ) were taken as the variable $\mathrm{X}_{2}$, while concentration of calcium chloride and sodium citrate were kept constant .

In the present study a $3^{2}$ full factorial design was employed to study the effect of independent variables, i.e. concentration of Gelrite $\left(\mathrm{X}_{1}\right)$ and the concentration of HPMC $\mathrm{K} 100 \mathrm{M}\left(\mathrm{X}_{2}\right)$ on dependent variables like \% cumulative drug release $\left(Q_{12}\right), \%$ drug content uniformity and viscosity. The high values of correlation coefficient for the dependent variables indicate a good fit. The equation may be used to estimate the response; a small error of variance was noticed in the replicates. [11]

\subsection{Evaluation of formulation}

\section{3a pH measurement}

All the prepared gelrite based in-situ solutions of Famotidine were checked for their $\mathrm{pH}$. The $\mathrm{pH}$ was measured using a 
calibrated $\mathrm{pH}$ meter at $25^{\circ} \mathrm{C}$. The measurements of $\mathrm{pH}$ of each data were in triplicate and the average values of preliminary trial batches (P1-P5) and factorial design batches (F1-F9) are shown in Table 1 and Table 3. [11]

\section{3b Gelling capacity}

Gelling capacity was determined by mixing the formulation with $0.1 \mathrm{~N} \mathrm{HCl}$ in the proportion of 3:15 and the gelation was assessed by visual examination. The time taken to form a gel and the integrity of the gel was noted.

A series of symbols were used to indicate the gelling time and gel retention capacity:

+ - Gelation after few min, weak gel formed.

++ - Gelation immediate, good gel formed.

+++ - Gelation immediate, stiff gel.

O.V. - Outside viscous ${ }^{[2,3]}$.

\section{3c Drug content uniformity}

Drug content estimation of the formulation was done by single point standardization method with spectrophotometer.

$5 \mathrm{ml}$ of formulation was transferred into a $250 \mathrm{ml}$ conical flask and $100 \mathrm{ml}$ of $0.1 \mathrm{~N} \mathrm{HCl}$ was added. The mixture was kept aside for $24 \mathrm{~h}$ with occasional shaking in a bottle shaker. After 24 h, $5 \mathrm{ml}$ of this mixture was taken and diluted up to $100 \mathrm{ml}$ with $0.1 \mathrm{~N} \mathrm{HCl}$ (Dilution factor $=2000$ times). A blank estimation was performed without the drug. The solutions were filtered and the absorbance was measured at $265 \mathrm{~nm}$ [11].

\section{3d Viscosity study}

The viscosity measurements were done by using Brooke a field DV-II+ viscometer using LV-3 spindle. The formulation was taken in a $100 \mathrm{ml}$ beaker and the angular velocity increased gradually from 10 to $100 \mathrm{rpm}$, with a wait period of $30 \mathrm{sec}$ at each speed. Viscosity was measured at room temperature and $100 \mathrm{ml}$ of the formulation was used to measure the viscosity. Upper surface of the formulation was adjusted to the mark given in the spindle to measure accurate viscosity. Although these formulations contain sodium citrate and calcium chloride, the hydrogen ion concentration is not sufficiently high to release calcium ions from the complex and gelation does not occur. Increasing the concentration of a dissolved or dispersed substance generally gives rise to increasing viscosity [7].

\section{3e In-vitro dissolution study}

The drug release study was carried out using USP type-II apparatus (Rotating Paddle type) at $37 \pm 0.5{ }^{\circ} \mathrm{C}$ and at $50 \mathrm{rpm}$ using $900 \mathrm{ml}$ of $0.1 \mathrm{~N} \mathrm{HCl}$ as a dissolution medium (rationale to study n=3). In-situ gel equivalent to $40 \mathrm{mg}$ of Famotidine (5 $\mathrm{ml}$ of formulation) was placed into a petri dish (5.5 cm i.d.) which was kept in the dissolution vessel and simulated gastric fluid was carefully added to the vessel avoiding any disturbance to the Petri dish. A sample solution of $10 \mathrm{ml}$ was withdrawn at predetermined time intervals, diluted and analyzed spectrophotometrically at $265 \mathrm{~nm}$. An equal amount of fresh 
dissolution medium was replaced immediately after withdrawal of the sample solution [11,13].

\section{3f Stability studies}

The formulation was subjected to accelerated stability studies as per ICH (The International Conference on Harmonization) guidelines. The most satisfactory formulation was sealed in an aluminum foil and stored at $30 \pm 2{ }^{\circ} \mathrm{C}$, $65 \pm 5 \% \mathrm{RH}$ and at $40 \pm 2{ }^{\circ} \mathrm{C}, 75 \pm 5 \% \mathrm{RH}$ for 2 months. Formulation was periodically removed and evaluated for physicochemical parameters and in-vitro drug dissolution [6].

\section{3g In-vivo study (Anti-ulcer activity)}

The formulation F4 was selected for investigation of anti-ulcer activity in rats by 'Ethanol induced method'. Ethanol induced method in rats: Randomly divided into three groups of five rats each.

Group-1: Control

Group-2: Standard (Standard marketed formulation, Famtac-40) .

Group-3: Test (In-situ Famotidine gel, Formulation-F4).

Animals were fasted for $24 \mathrm{~h}$ and allowed free access to water. The animals of group I received control vehicle (Water). The animals of groups II and III received standard marketed tablet (Famtac $40 \mathrm{mg}$, Dose: 12 $\mathrm{mg} / \mathrm{kg}$ ) and optimized formulation F4 (12 $\mathrm{mg} / \mathrm{kg}$ ) orally, respectively. Thirty minutes later, $1 \mathrm{ml}$ of absolute ethanol was given orally. Animals of group-1were sacrificed after $1 \mathrm{~h}$ and the stomachs were removed, cut along the greater curvature and subjected to measurement of ulcer index. Animals belonging to group-2 and group-3 were sacrificed after $4 \mathrm{~h}$ and $12 \mathrm{~h}$, respectively. Stomachs were subjected to measurement of ulcer index. Animals of group-3 were checked whether the gel was formed in the stomach of rats $[8,12]$.

Ulcer Severity is graded as:

0 - No ulcer

1- Superficial Ulcer

2- Deep ulcer

3- Perforation.

The Ulcer Index $\left(U_{I}\right)$ is calculated by the following equation:

$$
\begin{aligned}
& \mathbf{U}_{\mathrm{I}}=\mathrm{U}_{\mathrm{N}}+\mathrm{U}_{\mathrm{S}}+\mathrm{U}_{\mathrm{P}} * 10^{-1} \\
& \text { Where, } \mathbf{U}_{\mathrm{N}}=\text { Average of number of }
\end{aligned}
$$

ulcers/animal;

$\mathbf{U}_{\mathbf{S}}=$ Average of Severity Scores;

$\mathbf{U}_{\mathbf{P}}=$ Percentage of animals with ulcers.

The percentage of ulcer protection was determined as follows:

$\%$ Protective $=(\underline{\text { Control mean ulcer index }- \text { Test mean ulcer index })} \times 100$

\section{(Control mean ulcer index)}




\section{RESULTS AND DISCUSSION}

\subsection{Drug-excipients compatibility studies}

FT-IR study showed that there was no interaction between the drug and the polymers. Therefore, the drug and polymers are compatible. FT-IR Spectra of Famotidine (Pure drug) and drug-polymer mixture are shown in Fig. 1 and 2.

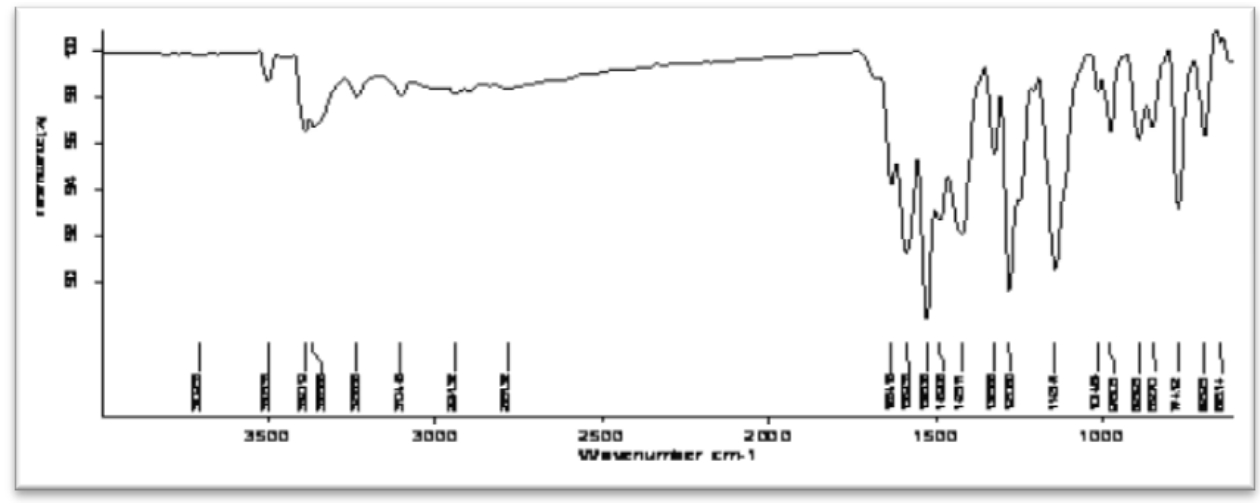

Fig. 1: FT-IR spectrum of pure drug (Famotidine)

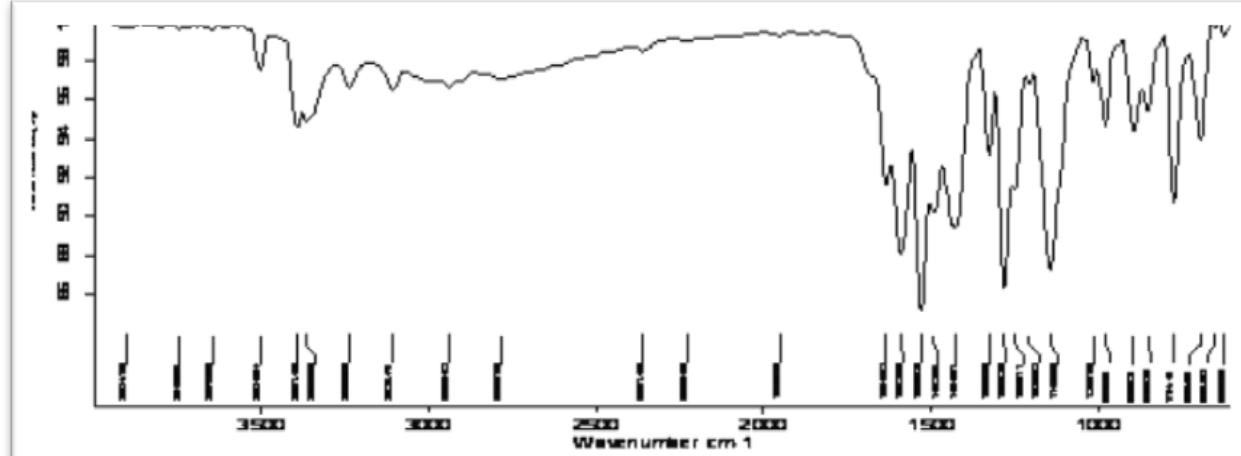

Fig. 2: FT-IR spectrum of physical mixture of drug + polymer + excipients

\subsection{Preliminary optimization trials}

Preliminary studies were carried out to optimize the gelrite concentration necessary for drug delivery. Batches P1 to P5 (Table-1) were prepared to study the effect of polymer concentration on the viscosity of the solutions, drug content, pH. The concentration of gelrite was varied from 0.25 , $0.50,0.75,1.00$ and $1.25 \%$. Gelrite based formulations P1-P5 were clear and $\mathrm{pH}$ of the formulations was varied from 5.98 to 6.10 .
Content uniformity of the developed formulations P1-P5 varied from 98.39 to 99.99, which are within acceptable range as specified in the Indian Pharmacopoeia (95\%105\%). The viscosity of formulations P4 and P5 were very high because of the higher concentration of gelrite which decreased the pourability of the solution. Thus gelrite concentration range of 0.25 to 0.75 was selected for $3^{2}$ factorial design studies. All the batches were prepared by using a constant 
amount of Famotidine (0.8\%), HPMC K100M (0.4\%),Sodium citrate $(0.17 \%)$, Calcium chloride (0.016\%) and Sodium propyl paraben $(0.02 \%)$.

\section{$3^{2}$ factorial design batches}

\section{pH measurement}

Gelrite based formulations F1 to F9 were checked for their $\mathrm{pH}$ using calibrated $\mathrm{pH}$ meter. $\mathrm{pH}$ of the formulations was varied from 5.96 to 6.12. The measurements of $\mathrm{pH}$ of each formulation were in triplicate and the average values are depicted in Table- 2 .

\section{Gelling capacity}

Gelling capacity of Gelrite based formulations F1 to F9 was determined by mixing the formulation with $0.1 \mathrm{~N} \mathrm{HCl}$. Due to the ion cross linking of the gelrite chains by the divalent cations, gelation occurs.

Formulations F1-F3 shows weak gel formation because of the comparatively less concentration of gelrite $(0.25 \%)$ to that of the other batches. Formulation F4 and F5 shows good gel formation having gelrite concentration $0.50 \%$. Stiff gel formation was observed in formulation F6 and F7 due to the higher concentration of gelrite and HPMC K100M. The viscosity of F8 and F9 was very high which was difficult to pour the solution. Observations of gelling capacity of prepared gel for gelrite based formulations are depicted in Table- 2 .

\section{Drug content uniformity}

The drug content was determined using single point standardization method. Content uniformity of the developed formulations F1 to F9 varied from 95.79 to 99.72 , which are within acceptable range as specified in Indian Pharmacopoeia for Famotidine (95\%-105\%). The drug content of the of $\mathrm{P}_{1}$ to $\mathrm{P}_{5}$ are depicted in Table-1while the data of drug content for batches F1 to F9 are depicted in Table-2.

Table 1: Results of preliminary trial batches for gelrite based in-situ gel

\begin{tabular}{cccccc}
\hline $\begin{array}{c}\text { Batch } \\
\text { No. }\end{array}$ & $\begin{array}{c}\text { Conc. of } \\
\text { Gelrite } \\
\text { (\%w/v) }\end{array}$ & $\begin{array}{c}\text { Conc. of } \\
\text { HPMC } \\
\text { K100M } \\
\text { (\%w/v) }\end{array}$ & $\begin{array}{c}\text { pH* }^{*} \\
\text { (Average } \pm \text { S.D.) }\end{array}$ & $\begin{array}{c}\text { Viscosity** } \\
\text { (cps) }\end{array}$ & $\begin{array}{c}\text { Drug content* } \\
\text { (\%) } \\
\text { (Average } \pm \text { S.D.) }\end{array}$ \\
\hline $\mathrm{P}_{1}$ & 0.25 & 0.4 & $6.10 \pm 0.011$ & 965.79 & $99.65 \pm 1.193$ \\
$\mathrm{P}_{2}$ & 0.50 & 0.4 & $6.07 \pm 0.020$ & 2735.42 & $99.66 \pm 1.160$ \\
$\mathrm{P}_{3}$ & 0.75 & 0.4 & $6.02 \pm 0.025$ & 4553.03 & $98.39 \pm 1.017$ \\
$\mathrm{P}_{4}$ & 1.00 & 0.4 & $5.99 \pm 0.015$ & $-\cdots$ & $99.99 \pm 2.245$ \\
$\mathrm{P}_{5}$ & 1.25 & 0.4 & $5.98 \pm 0.005$ & $-\cdots$ & $99.28 \pm 1.081$ \\
\hline
\end{tabular}

* Average of three trials ** Viscosity measured at $20 \mathrm{rpm}$ 
Table 2: Formulation chart for gelrite based in-situ gel by using $3^{2}$ full factorial designs

\begin{tabular}{ccccccc}
\hline $\begin{array}{c}\text { Batch } \\
\text { No. }\end{array}$ & $\begin{array}{c}\text { Amount of } \\
\text { drug } \\
\text { (mg) }\end{array}$ & $\begin{array}{c}\text { Conc. of } \\
\text { Gelrite } \\
\text { (mg) }\end{array}$ & $\begin{array}{c}\text { Conc. of } \\
\text { HPMC } \\
\text { K100M } \\
\text { (mg) }\end{array}$ & $\begin{array}{c}\text { Conc. of } \\
\text { sodium } \\
\text { citrate } \\
\text { (mg) }\end{array}$ & $\begin{array}{c}\text { Conc. of } \\
\text { calcium } \\
\text { chloride } \\
\text { (mg) }\end{array}$ & $\begin{array}{c}\text { De-ionized } \\
\text { water }\end{array}$ \\
\hline F1 & 800 & 250 & 300 & 170 & 160 & \\
F2 & 800 & 250 & 400 & 170 & 160 & \\
F3 & 800 & 250 & 500 & 170 & 160 & \\
F4 & 800 & 500 & 300 & 170 & 160 & q.s. up to 100 \\
F5 & 800 & 500 & 400 & 170 & 160 & ml \\
F6 & 800 & 500 & 500 & 170 & 160 & \\
F7 & 800 & 750 & 300 & 170 & 160 & \\
F8 & 800 & 750 & 400 & 170 & 160 & \\
F9 & 800 & 750 & 500 & 170 & 160 & \\
\hline
\end{tabular}

All the batches were prepared using constant amount of

- Famotidine: $0.8 \% \mathrm{w} / \mathrm{v}$,

- Sodium citrate: $0.17 \% \mathrm{w} / \mathrm{v}$,

- Calcium chloride: $0.016 \% \mathrm{w} / \mathrm{v}$,

- Sodium propyl paraben: $0.02 \% \mathrm{w} / \mathrm{v}$

\section{Viscosity study}

Formulations F1-F9 were evaluated for their rheological property using Brookfield viscometer. All the formulations exhibited pseudo-plastic rheology, as shown by shear thinning and a decrease in the viscosity with increase in angular velocity. Results of the rheological studies show that as the concentration of polymers increases from F1 to F9 formulation, viscosity also increases.

The viscosity of the gelrite based in-situ formulations of P1 to P5 and batches F1 to F9 are depicted in Table-1 and Figure-3, respectively.

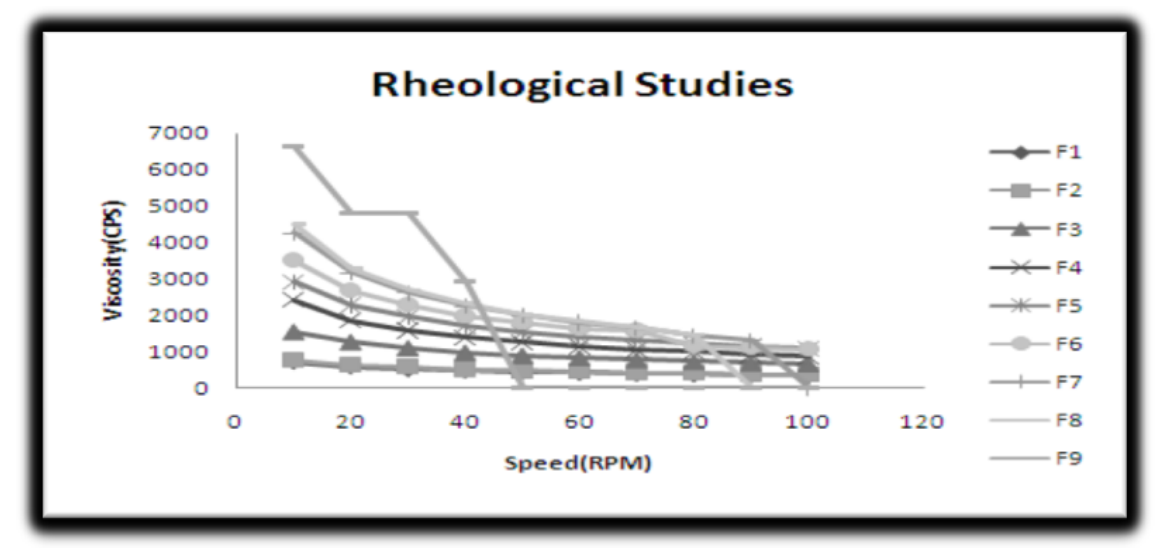

Fig. 3: Rheological studies on formulation F1-F9 


\section{In-vitro dissolution study}

In-vitro dissolution study was carried out for

$12 \mathrm{~h}$. The amount of cumulative drug release from the gel at the end of $12 \mathrm{~h}$ was found to be highest in formulation F1 and lowest in F9 which could be due to increase in the concentration of polymers. The dissolution profiles for gelrite based in-situ gels from batches F1 to F9 are shown in Figure-4.

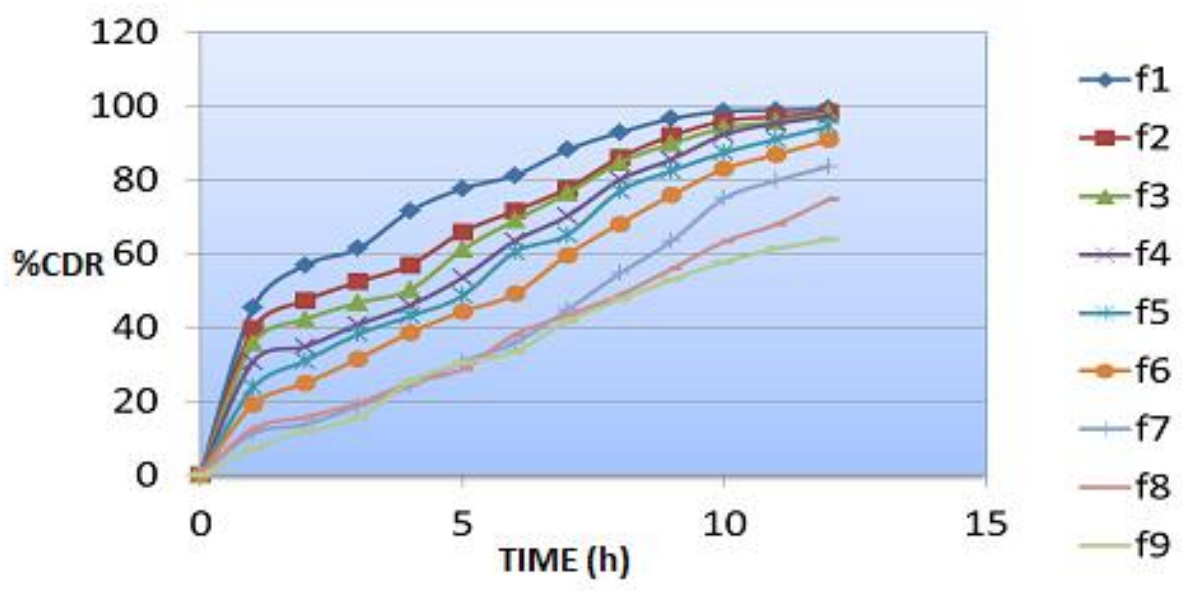

Fig. 4: In-vitro dissolution studies of gelrite based formulations batch F1-F9.

\section{Selection of the best batch}

The selection of the best batch depends on gelling capacity, viscosity and drug content of formulation. Formulation F4 was selected the best formulation because of its good gelling capacity and optimum viscosity compared to other formulations. F4 shows the drug content 98.84 which is within the acceptable range as specified in the Indian Pharmacopoeia. The viscosity of batch F4 is $1857.60 \mathrm{cps}$ (at $20 \mathrm{rpm}$ ) which is easy for swallowing and good ability for gelation immediately after oral administration. In the batches F1 to F3 the rate of drug release are very high because of the low concentration of polymers and weak gel formation. Formulations F5 to F9 showed less cumulative drug release compared to F4. The www.ijapbjournal.com amount of drug released for the batch F4 after 12 hours was $97.23 \%$. So, the batch F4 was selected for further study.

\section{In-vivo study (Anti-ulcer activity)}

The anti-ulcer activity was evaluated by ethanol induced ulcer in rats to check the effect of drug release in a sustained manner from the gel by assessing the ulcer index. In group 3 which served as a test, ulcers were reduced compared to group 1 (control) and 2 (standard). The gel formation takes place inside the stomach of the test group rats and was found after $12 \mathrm{~h}$. The ulcer index for group 1, 2 and 3 are 35.4, 14 and 7.2 respectively. The formulation $\mathrm{F} 4$ has decreased the intensity of gastric mucosal damage induced by ethanol and showed a protection index of $79.66 \%$ when compared 
to control, whereas standard marketed tablet of Famotidine has shown $60.45 \%$ of protection induced by ethanol when compared to control. Graph of \% protective $\mathrm{v} / \mathrm{s}$ groups shows that sustained release of the drug from in-situ formulation has better $\%$ protective effect on alcohol induced ulcer compared to that of conventional Famotidine tablet. Results of ulcer index for ethanol induced model are shown in Figure-7.

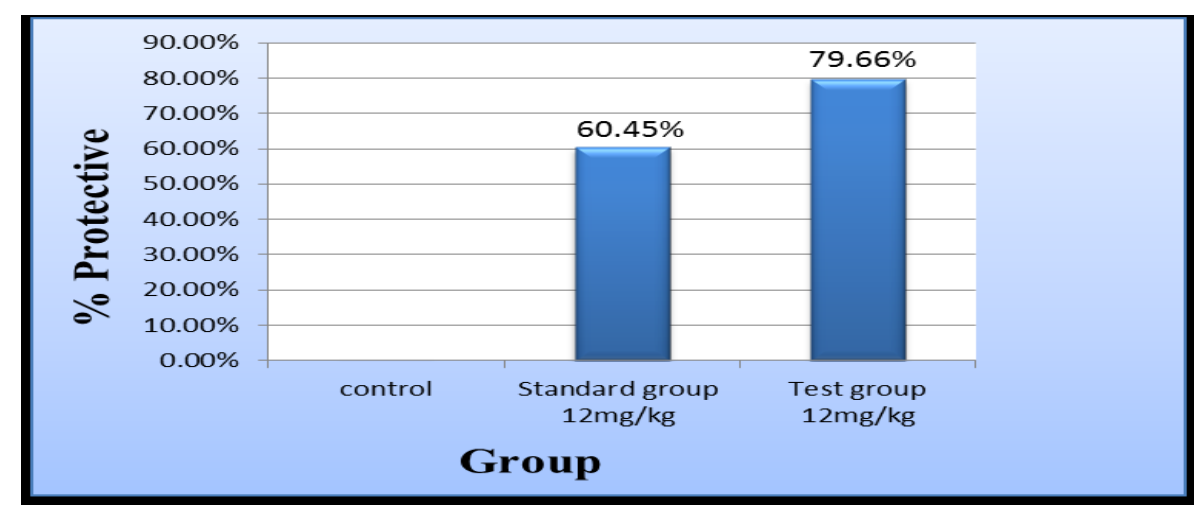

Fig.7: Percentage protection of drug in ethanol induced ulcer.

\section{Release mechanism}

The results of regression analysis from Zero order, First order, Higuchi model and Korsmeyer-Peppas model (Table-4) of best formulation F4 show that zero order gave the highest value of $\mathrm{R}^{2}$ with significant difference to that of other models. From these results it was concluded that F4 follows Zero order kinetic because of the good linearity obtained by this model.

\section{Stability study}

Stability studies were carried out on the most satisfactory formulation as per ICH Guidelines Q1C. The most satisfactory formulations were stored in sealed aluminum foil at $30 \pm 2^{\circ} \mathrm{C}, 65 \pm 5 \% \mathrm{RH}$ and at $40 \pm 2{ }^{\circ} \mathrm{C}$, $75 \pm 5 \% \mathrm{RH}$ for 2 months. The formulation was periodically evaluated for physicochemical parameters and in-vitro drug release. Figure-5 and Figure- 6 showed that there were no significant changes found after 2 month stability study.

Table3: Evaluation of physicochemical parameters of formulation F4 (After stability).

\begin{tabular}{cc|ccc}
\hline \multicolumn{2}{c|}{$\begin{array}{c}\text { Physicochemical } \\
\text { Parameters }\end{array}$} & \multicolumn{3}{c}{ Time (Days) } \\
\hline pH & $\mathbf{A}^{*}$ & 6.07 & 6.04 & 6.12 \\
& $\mathbf{B}^{* *}$ & & 6.08 & 6.07 \\
Drug Content (\%) & $\mathbf{A}^{*}$ & 98.84 & 97.34 & 98.17 \\
& $\mathbf{B}^{* *}$ & & 96.51 & 95.68 \\
Viscosity(cps)*** & $\mathbf{A}^{*}$ & 1857.60 & 1679.64 & 1589.37 \\
& $\mathbf{B}^{* *}$ & & 1704.89 & 1649.65 \\
\hline
\end{tabular}

${ }^{*} \mathrm{~A}: 30 \pm 2^{\circ} \mathrm{C}$ and $65 \pm 5 \% \mathrm{RH} \quad * * \mathrm{~B}: 40 \pm 2^{\circ} \mathrm{C}$ and $75 \pm 5 \% \mathrm{RH} \quad{ }^{* * *}$ Viscosity measured at $20 \mathrm{rpm}$ 
Table 4: Release kinetic for gelrite based formulation $F 4$

\begin{tabular}{ccccc}
\hline \multirow{2}{*}{ Batch No. } & \multicolumn{4}{c}{ Regression } \\
\cline { 2 - 5 } & $\begin{array}{c}\text { Zero order } \\
\text { kinetic }\end{array}$ & $\begin{array}{c}\text { First order } \\
\text { kinetic }\end{array}$ & $\begin{array}{c}\text { Higuchi } \\
\text { kinetic }\end{array}$ & $\begin{array}{c}\text { Korsmeyer- } \\
\text { Peppas }\end{array}$ \\
\hline F4 & 0.9886 & 0.910 & 0.9667 & 0.9478 \\
\hline
\end{tabular}

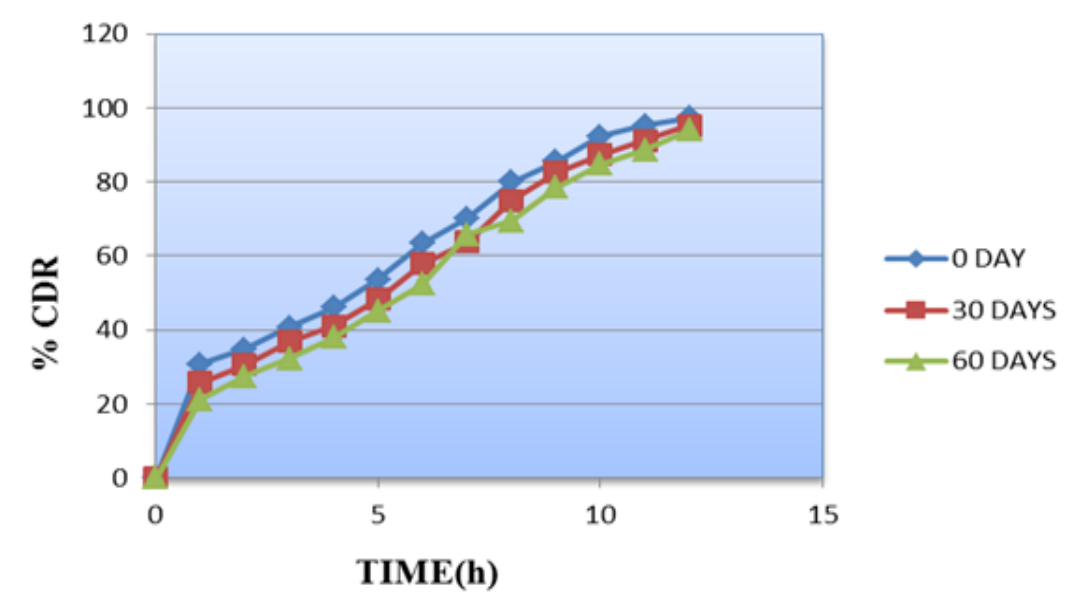

Fig. 5: In-vitro dissolution studies of F4 (A) (After stability). [A: $30 \pm 2^{\circ} \mathrm{C}$ and $65 \pm 5 \% \mathrm{RH}$ ]

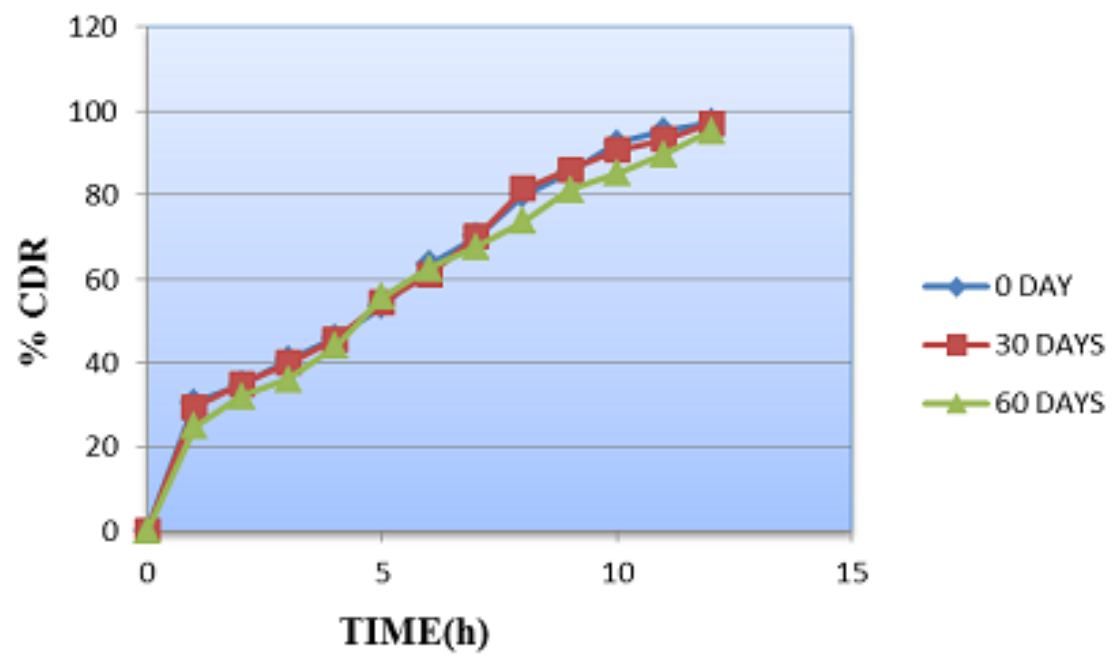

Fig. 6: In-vitro dissolution study of F4 (B) (After stability). [B: $40 \pm 2^{\circ} \mathrm{C}$ and $75 \pm 5 \% \mathrm{RH}$ ]

OPTIMIZATION BY USING $\mathbf{3}^{2}$ FULL The viscosity is an important variable

\section{FACTORIAL DESIGNS}

Factorial equation for viscosity

Viscosity $=2046.45+1458.023 \mathrm{X}_{1}+$

$518.55 \mathrm{X}_{2}+238.44 \mathrm{X}_{1}^{2}+5.66 \mathrm{X}_{2}^{2}+336.59 \mathrm{X}_{1}$ $\mathrm{X}_{2}$

www.ijapbjournal.com because it affects the gelation of the solutions, the flow of the formulation and time required for the gelation. The viscosity is dependent on the concentration of the polymer and concentration of the HPMC K100M. The 
viscosity of the gelrite solutions varied from 583.87 cps to 4782.98 cps which was measured at $20 \mathrm{rpm}$ and showed good correlation coefficient as 0.9931 . Results of the equation indicate that the effect of $X_{1}$ (concentration of gelrite) is more significant than $\mathrm{X}_{2}$ (concentration of HPMC K100M). The $\mathrm{b}_{0}$ equals to 2046.45 was the arithmetic mean of all nine trials. The positive $\mathrm{X}_{1}$ and $\mathrm{X}_{2}$ coefficient indicates there is increase in the viscosity with increased concentration of both gelrite and as well as HPMC K100M.

\section{Factorial equation for drug content}

Drug content $=98.92-0.092 \mathrm{X}_{1}+0.544 \mathrm{X}_{2}-1.32$

$\mathrm{X}_{1}^{2}-1.437 \mathrm{X}_{2}^{2}+0.359 \mathrm{X}_{1} \mathrm{X}_{2}$

The drug content varied from $95.79 \%$ to 99.72\% in batches F1 to F9 gelrite based insitu formulations of Famotidine and showed good correlation coefficient as 0.9706 . Results of the equation indicate that the effect of $\mathrm{X}_{2}$ (concentration of HPMC $\mathrm{K} 100 \mathrm{M}$ ) is more significant than $\mathrm{X}_{1}$ (concentration of gelrite). So, the effect of the concentration of the HPMC K100M was more responsible for the drug content of the in-situ formulations than the concentration of gelrite.

\section{Factorial equation for \%CDR}

$\% \mathrm{CDR}=94.45-12.26 \mathrm{X}_{1}-4.596 \mathrm{X}_{2}-4.649 \mathrm{X}_{1}^{2}-$ $7.857 \mathrm{X}_{2}^{2}-0.412 \mathrm{X}_{1} \mathrm{X}_{2}$

The amount of drug released is an important parameter for sustained release action of the in-situ gel of Famotidine. The amount of drug released after 12 hours from the in-situ gel of Famotidine varied from $63.78 \%$ to $99.30 \%$ in formulations F1-F9 and showed good www.ijapbjournal.com linearity. Results of the equation indicated that both the effect of the concentration of gelrite $\left(\mathrm{X}_{1}\right)$ and the effect of the concentration of HPMC K100M $\left(\mathrm{X}_{2}\right)$ were in negative values, but $\mathrm{X}_{1}$ was more significant than the $\mathrm{X}_{2}$. So, the concentration of $X_{1}$ was more effective as for controlled release action of the gels than the concentration of $X_{2}$. The negative $X_{1}$ and $X_{2}$ coefficients indicate there is decrease in cumulative drug release with increase in the concentration of both gelrite and as well as HPMC K100M.

\section{CONCLUSION}

In the present study, an attempt was made to formulate and evaluate oral in-situ gel of Famotidine for the treatment of stomach ulcer. The main interest in such a dosage form was to target the drug to its absorption site by preparing gastro retentive drug delivery system as the absorption window of Famotidine is stomach. The possible interaction between the drug and excipient was studied by FT-IR spectroscopy which showed that there was no interaction between the selected drug and polymers under study.

Oral in-situ gel of Famotidine was prepared by using Famotidine and other additives as shown in formulation chart. In this study, various formulations were developed using gelrite and HPMC K100M as polymers, calcium chloride as a cross linking agent. F4 was selected as best formulation because of its good gelling capacity and showed $97.23 \%$ cumulative drug release after $12 \mathrm{~h}$. The 
formulation F4 followed zero order kinetic which describes that the rate of drug release is independent of its concentration. Results of the stability study showed that there were no significant changes found after 2 months.

The results of optimization by $3^{2}$ full factorial design revealed that the concentration of gelrite and concentration of HPMC K100M significantly affect the dependent variables viscosity, drug content and \%CDR $\left(\mathrm{Q}_{12}\right)$. The in-vivo study shows significant anti-ulcer effect of the sustained release gelrite based

\section{REFERENCES}

1. Attwood, D, Miyazaki S, Kawasaki, N, Kubo, W, Endo K. Comparison of insitugelling formulations for the oral delivery of cimetidine. Int $J$ Pharm., 220:161-8.

2. Attwood D, FujiwaraM, Miyazaki S, Kubo W, Itoh K, KonnoY, Dairaku M. The effect of taste masking agents on in-situ gelling pectin formulations for oral sustained delivery of paracetamol and ambroxol. Int J Pharm., 2005; 297:38-49.

3. BalasubramaniumJ, Kant S, Pandit J.K. Invitro and in-vivo evaluation of the gellan gum based ocular delivery system for Indomethacin. Acta Pharm., 2003; 53:251261.

4. EchizenH, Ishizaki T. Clinical Pharmacokoinetics of famotidine. Clin Pharmacokoinetic. 1991; 21:1780-94. in-situ gel of Famotidine compared to conventional marketed tablet over long period of time. These in-situ gels are, thus, suitable for oral sustained release of Famotidine.

\section{ACKNOWLEDGEMENT}

The authors are thankful to Medreich Steri Lab Pvt. Ltd., Bangalore for providing the gift sample of Famotidine; Colorcon Asia Pvt. Ltd., Goa for providing gift sample of HPMC K100M.

5. Hwang S.J, Park H, ParkK. Gastric retentive drug-delivery systems. Crit Rev Ther Drug Carrier Syst., 1998; 15: 243-84.

6. ICH guidelines. [cited 2010 Dec 16];

Available from: URL:

http://www.tga.health.gov.au/docs/pdf/ euguide/ich/273699r2en.pdf

7. Jaya Raj Kumar K, Jayachandran E, Srinivas G.M. Formulation and evaluation of $\mathrm{pH}$ induced Povidone Iodine in-situ gel for oraltrush. J Pharm Sci Res., 2010; 2(5): 294-301.

8. Khazaei M, Salehi H.Protective effect of falcaria vulgaris extract on ethanol induced gastric ulcer in rat. Iranian $J$ Pharmacol\&Ther., 2006; 5:43-6.

9. Miyazaki S, Aoyama H, Kawasaki N, Kubo W, Attwood D.In-situ gelling gellan formulations as vehicles for oral drug delivery. J Control Rel., 1999; 60:287-95.

10. Patel R.P, Dadhani B, Ladani R, Baria A.H, Patel Jigar. Formulation, evaluation and 
optimization of stomach specific in-situ gel of clarithromycin and metronidazole benzoate. Int J of Drug Deliv., 2010a; 2:141-53.

11. Patel R.P, Baria A.H, Pandya N.B, Tank H.M. Formulation, evaluation and optimization of stomach specific in-situ gel of ranitidine hydrochloride. Int $J$ of Pharm Sci Nanotech., 2010b; 3(1):834-43.

12. Ramachandran S, Poovi G, Dhanaraju M.D. Evaluation of gastric and duodenal antiulcer activity of famotidine formulation in experimental animals. J Pharmacol Toxicol., 2010; 6: 189-95.

13. Rohith G, Bhimagoni K.S, Anegundha S. Floating drug delivery of a locally acting $\mathrm{H}_{2}$-antagonist: An approach using an insitu gelling liquid formulation. Acta Pharm; 2009; 59:345-54.
14. Sood A, Panchagnula R. Design of controlled release delivery systems using a modified pharmacokinetic approach: a case study for drugs having a short elimination half-life and a narrow therapeutic index. Int J Pharm., 2003; 261:27-41.

15. Soppimath K.S, Kulkarni R.A, Rudzinski W.E, Aminabhavi T.M. Microspheres as floating drug delivery systems to increase gastric retention of drugs. Drug Metab Rev., 2001; 33:149-60.

16. St. Louis. Drug Facts and Comparisons. $50^{\text {th }}$ edition, $1996, \mathrm{pp} .1872-74$. 